Research

\title{
Effects of chronic widespread pain on the health status and quality of life of women after breast cancer surgery Carol S Burckhardt* and Kim D Jones
}

\author{
Address: Primary Care, School of Nursing, Oregon Health \& Science University, Portland, Oregon, USA \\ Email: Carol S Burckhardt* - burckhac@ohsu.edu; Kim D Jones - joneskim@ohsu.edu \\ * Corresponding author
}

Published: 28 April 2005

Health and Quality of Life Outcomes 2005, 3:30 doi:10.1 186/1477-7525-3-30

This article is available from: http://www.hqlo.com/content/3/I/30

(C) 2005 Burckhardt and Jones; licensee BioMed Central Ltd.

This is an Open Access article distributed under the terms of the Creative Commons Attribution License (http://creativecommons.org/licenses/by/2.0), which permits unrestricted use, distribution, and reproduction in any medium, provided the original work is properly cited.
Received: 0I March 2005

Accepted: 28 April 2005

\begin{abstract}
Background: Most research and treatment of post-breast cancer chronic pain has focused on local or regional pain problems in the operated area. The purpose of this pilot study was to compare and contrast the pain characteristics, symptom impact, health status, and quality of life of post-breast cancer surgery women with regional chronic pain versus those with widespread chronic pain.
\end{abstract}

Methods: A cross-sectional, descriptive design compared two groups of women with chronic pain that began after surgery: regional pain $(n=I I)$ and widespread pain $(n=12)$. Demographics, characteristics of the surgery, as well as standardized questionnaires that measured pain (Brief Pain Inventory (BPI), Short Form McGill Pain Questionnaire (MPQ-SF)), disease impact (Fibromyalgia Impact Questionnaire (FIQ), Functional Assessment of Cancer Therapy-Breast (FACT-B)), health status (Medical Outcomes Short Form (SF-36)) and quality of life (Quality of Life Scale (QOLS)) were gathered.

Results: There were no significant differences between the groups on any demographic or type of surgery variable. A majority of both groups described their pain as aching, tender, and sharp on the MPQ-SF. On the BPI, intensity of pain and pain interference were significantly higher in the widespread pain group. Differences between the two groups reached statistical significance on the FIQ total score as well as the FACT-B physical well-being, emotional well-being and breast concerns subscales. The SF-36 physical function, physical role, and body pain subscales were significantly lower in the widespread pain group. QOLS scores were lower in the widespread pain group, but did not reach statistical significance.

Conclusion: This preliminary work suggests that the women in this study who experienced widespread pain after breast cancer surgery had significantly more severity of pain, pain impact and lower physical health status than those with regional pain.

\section{Background}

Breast cancer is the most common form of cancer among women in the United States, Canada and Europe [1,2]. A sharp increase in incidence has been seen over the past two decades due in large part to use of mammography and subsequent earlier detection of disease. Earlier detection and treatment has led to increased survival rates approaching $90 \%$ for noninvasive cancers $[3,4]$ Thus, a 
large majority of women with breast cancer will survive for many years after the initial diagnosis and treatment. Because they are living longer, living well with a good quality of life has become a high priority $[5,6]$.

A recent study of health-related quality of life (HRQOL) concluded that most women treated for early-stage breast cancer have generally high HRQOL when compared to norms for the general population [7]. Unfortunately, long-term disease and treatment-related symptoms, such as chronic pain, can have wide-ranging consequences for health, functioning, and life quality [8-10]. Several researchers have reported that a substantial number of long-term breast cancer survivors experience chronic pain that interferes with physical functioning, mood, work, relationships, sleep, and enjoyment of life [11-15].

Chronic localized or regional pain after breast cancer surgery is a common and well-recognized problem with prevalence rates ranging from 20 to $65 \%$ [16-18]. Much of this pain is believed to be neuropathic phenomena due to transsection of nerves during surgery, nerve entrapment, axillary hematoma, or development of a traumatic neuroma on the operated side [19-21]. In addition, significantly higher rates of chronic pain on the affected side have been reported in patients who have had a mastectomy with reconstruction versus those who have had a mastectomy alone [18] and those who have undergone extensive axillary node dissection $[22,23]$.

However, growing evidence exists that neuropathic phenomena alone do not explain all of the chronic pain experienced by post-surgery patients. Many breast cancer patients suffer from widespread, diffuse persistent pain that may be due to the chronic activation of nociceptors $[24,25]$. Reports on mastectomy with or without breast reconstruction have found a significant risk for development of fibromyalgia (FMS) [26], a specific syndrome of widespread chronic pain that affects approximately $2-5 \%$ of the female adult populations in the United States and many other countries $[27,28]$.

Recent evidence has documented central sensitivity due to chronic input from peripheral nerves as a major cause of chronic pain in FMS patients [29,30]. And further, that trauma, especially to the upper body, is more likely to eventually lead to diffuse, widespread pain [31]. In both breast cancer patients and FMS patients, upper body trauma may be a factor in the onset and persistence of chronic widespread pain [32,33]. These findings are important because dysfunction, disability and detriments to quality of life are substantial in the FMS population $[34,35]$. But as yet, diffuse, widespread chronic pain among post-surgery breast cancer patients has not received the same attention as localized neuropathic pain.
In summary, until now, most work in post-breast cancer chronic pain has focused on local or regional pain problems in the operated area. Yet, a substantial number of post-breast cancer surgery women may have chronic widely diffuse pain that limits their functioning and decreases their overall life quality. The purpose of this pilot study was to compare and contrast the pain characteristics, syndrome impact, health status, and quality of life of post-breast cancer surgery women with localized or regional chronic pain versus post-breast cancer surgery women with widespread chronic pain.

\section{Methods \\ Design}

This pilot project used a cross-sectional, descriptive design. Participants responded to a battery of self-report questionnaires. The project focused on gathering preliminary descriptive data using well-validated scales.

\section{Participants}

Participants were recruited through an advertisement placed in a local newspaper, and mailings containing the advertisement to a database of women with FMS at a university out patient FMS clinic and to a university breast cancer clinic. The target sample size was 30 .

The advertisement invited women, who believed that they met the criteria listed below, to call and leave a message at a specified number. An investigator called the woman, answered any questions about the study and then invited the woman to come to the clinic at a specified time if it appeared that she met criteria. Written informed consent for the data collection was obtained at the clinic visit after eligibility requirements were confirmed by the investigator.

\section{Selection of participants}

Women were eligible if they had had a simple mastectomy, lumpectomy, or modified radical mastectomy for breast cancer and included those with expansion or breast reconstruction at the time of initial surgery or subsequent breast reconstruction. Other specific inclusion criteria included: (1) adults at least 18 years of age; (2) first time primary diagnosis of breast cancer; (3) post-mastectomy for at least 6 months; (4) at least 3 months post-primary adjuvant treatment (radiation, cytotoxic chemotherapy); (5) cancer-free by their own report and having seen their physician within the last year; and, (6) current chronic pain by their own report that began after the breast cancer surgery. Exclusion criteria included: (1) breast surgery for cosmetic reasons or prophylactic mastectomy; and, (2) other painful or disabling medical conditions, such as arthritis. 


\section{Data collection}

Demographic and cancer history information was obtained using a checklist and short answer questionnaire. Demographic variables included age, ethnic background, marital status, education, employment status, and occupation. Cancer history variables included date of surgery, type of breast cancer surgery, type of breast reconstruction surgery, adjuvant therapy, present cancer status.

\section{Instruments for measuring pain characteristics}

1. Short Answer Questions related to location, onset, extent, and quality of the pain as well as any medications for pain.

2. Body Diagram developed for use in FMS patients (Chris Henriksson, unpublished data). It was used in this study to distinguish regional from widespread pain. The subject was asked to mark each of 36 segments with a number between 1 and 10 signifying intensity of pain if she had any pain in that segment. This enabled us to distinguish regional pain (limited to 1 or 2 quadrants upper, lower, right or left) and widespread pain that involved 3 or 4 quadrants as well as obtain some measure of the intensity of the pain at the time of the data collection. The use of quadrants to distinguish regional from widespread pain follows the American College of Rheumatology criteria for the classification of FMS [36].

3. The Brief Pain Inventory (BPI) which provides information on intensity (sensory dimension) of pain and the degree to which pain interferes with function (reactive dimension). The BPI uses 0 to 10 numeric rating scales and asks patients to rate their pain at the time of responding to the questionnaire as well as at its worst, least, and average over the previous week. Using the same rating scales, it asks the patient to rate the degree of interference with general activity, mood, walking and other physical activity, work, social activity, relationships with others and sleep. Developed originally for use in cancer treatment and research, the BPI has been well validated in cancer patients $[37,38]$.

4. The Short-form McGill Pain Questionnaire a 15-item form of the longer McGill Pain Questionnaire [39]. Each descriptor is rated on a 4-point scale. Evidence for validity in cancer and FMS has been established [40,41]. This questionnaire was used to characterize the similarities and differences in pain descriptions between the two groups.

\section{Instruments for measuring syndrome impact, health status and quality of life}

1. The Fibromyalgia Impact Questionnaire a 10-item instrument that measures difficulties with activities of daily living and symptoms of pain, fatigue, morning tiredness, stiffness, job difficulty, depression and anxiety along with amount of work missed and overall well-being during the past week [42]. The instrument has been validated for FMS patients and discriminates between FMS, rheumatoid arthritis and healthy people. It is scored as individual items and as a total score that indicates more FMS impact. This instrument was used to measure overall symptom impact of widespread pain. Scores on the individual items are standardized from 0 to 10 and a total score can range from 0 to 100 with a higher score indicating greater impact (Current scoring information can be obtained at http://www.myalgia.com).

2. Functional Assessment of Cancer Therapy (FACT-B) a 44-item self-report questionnaire designed to measure multidimensional health-related quality of life in patients with breast cancer [43]. The FACT-B consists of the FACT$\mathrm{G}$ plus additional items that make up the breast cancer subscale [44]. The FACT-G contains five subscales: physical, functional, social/family and emotional well being and satisfaction with doctors. Each item is rated on a 5point scale with 0 equal to "not at all" and 4 equal to "very much." Items are reversed if necessary and summed so that a higher subscale score indicates higher well being or satisfaction. All ratings on the FACT-B are completed in terms of the past seven days.

3. The SF-36 a 36-item scale that measures 9 domains of health including physical functioning, physical role limitations, bodily pain, general health, vitality, social functioning, emotional role limitations, mental health and change in health [45]. Higher scores indicate better health. The SF-36 has been used in numerous studies of cancer patients and has evidence of validity in both cancer and widespread pain patient groups $[46,47]$. We used this instrument as the measure of health status.

4. The Quality of Life Scale (QOLS) a 16-item nonhealth focused scale that measures satisfaction with multiple domains of life $[48,49]$. It uses a 1 to 7 point rating scale anchored with the words terrible and delighted. A higher total score indicates higher quality of life. Use in chronic illness populations, including a small group of cancer patients with ostomies, has been validated.

\section{Statistical analysis}

All data were analyzed using the SPSS version 12 statistical software package. Descriptive statistics (frequencies, means, standard deviations, and percentages) were used to characterize the sample. Preliminary inferences using ttests for two independent samples and Chi-square for proportions were made. Because normality and equality of variance could not be assumed in the small samples, Q-Q plots and Levene tests were carried out. Q-Q plots revealed no serious deviations from normality. Levene tests for equality of variances enabled us to adjust the significance 
Table I: Demographic and Breast Cancer Surgery and Treatment Characteristics by Pain Extent Group

\begin{tabular}{lcc}
\hline Variable & $\begin{array}{c}\text { Regional Pain } \\
\mathrm{n}=\mathrm{II}\end{array}$ & $\begin{array}{c}\text { Widespread Pain } \\
\mathrm{n}=\mathrm{I}\end{array}$ \\
\hline Age (years) & $56.8(5.5)$ & $58.7(8.6)$ \\
Education (years) & $16.0(2.4)$ & $14.8(3.2)$ \\
Ethnic (\% white) & 91 & 100 \\
Marital Status (\% married) & 73 & 69 \\
Employment (\% employed) & 63 & 67 \\
Time since Surgery (years) & $5.9(2.9)$ & $5.4(3.6)$ \\
Type of Surgery & 36 & 33 \\
$\quad$ Lumpectomy (\%) & 64 & 67 \\
Mastectomy (\%) & 54 & 67 \\
Brillary Node Dissection (\%) & 18 & 0 \\
Tissue Expansion (\%) & 100 & 80 \\
\hline Radiation Therapy (\%) & 60 & $2.9(3.0)$ \\
\hline Time Since Radiation (years) & $4.2(3.2)$ & 64 \\
\hline Chemotherapy (\%) & 55 & $2.8(1.6)$ \\
\hline Time Since Chemo (years) & $5.5(2.4)$ & 75 \\
\hline Anti-estrogen Therapy (\%) & 73 & \\
\hline Current Anti-estrogen & 36 & \\
Therapy (\%) & & \\
\hline
\end{tabular}

Numbers are means and standard deviations except when noted as percentages

levels of the t-tests if the assumption of equal variance was not met for a variable. Alpha level for a significant difference was set at 0.01 because of the number of variables. As a check on the validity of the parametric test, we also ran a nonparametric analysis for 2 independent groups (Mann Whitney U) and found the same variables to be significant as on the t-test. Formal directional hypotheses were not made a priori. However, we expected to find that the group with widespread pain would have more severe pain impact, poorer health status and lower quality of life than the group with regional pain only.

\section{Results}

In all 30 women replied to the advertisement, 27 expressed initial interest in the study after talking with an investigator by telephone, and 23 scheduled and kept a clinic appointment at the university that reviewed and approved the study, signed the written consent form and completed data collection. No data were collected from the 7 women who inquired about the study but did not sign a consent form. The regional pain group was comprised of 11 women who reported pain only in the upper
Table 2: Pain Characteristics by Pain Extent Group

\begin{tabular}{lcc}
\hline Variable & $\begin{array}{c}\text { Regional Pain } \\
\mathrm{n}=\mathrm{II}\end{array}$ & $\begin{array}{c}\text { Widespread Pain } \\
\mathrm{n}=12\end{array}$ \\
\hline $\begin{array}{l}\text { When did pain begin } \\
\text { Immediately }\end{array}$ & 63 & 56 \\
Weeks later & 12 & 11 \\
$\quad$ Months later & 25 & 33 \\
Pain & & \\
$\quad$ Constant & 20 & 50 \\
$\quad$ Intermittent & 80 & 50 \\
Worse when Depressed & 22 & 50 \\
Worse when Fatigued & 67 & 80 \\
Relationship to Activity & & \\
(Worse) & & 70 \\
$\quad$ Exercise & 44 & 36 \\
Clothing Contact & 11 & 73 \\
Rest & 33 & 56 \\
Cold & 25 & 30 \\
Relief with Medication & & 70 \\
Yes & 22 & 0 \\
Somewhat & 34 & \\
No & 44 & \\
\hline
\end{tabular}

Numbers are percentages

Table 3: Short-Form McGill Pain Questionnaire by Pain Extent Group

\begin{tabular}{lcc}
\hline Variable & $\begin{array}{c}\text { Regional Pain } \\
(\mathrm{n}=\mathrm{II})\end{array}$ & $\begin{array}{c}\text { Widespread Pain } \\
(\mathrm{n}=12)\end{array}$ \\
\hline Throbbing & 27 & 17 \\
Shooting & 46 & 50 \\
Stabbing & 64 & 42 \\
Sharp & 54 & 58 \\
Cramping & 18 & 33 \\
Gnawing & 0 & $58^{*}$ \\
Hot-Burning & 9 & 50 \\
Aching & 73 & 83 \\
Heavy & 45 & 50 \\
Tender & 55 & 67 \\
Splitting & 18 & 33 \\
Tiring-Exhausting & 9 & $67^{*}$ \\
Sickening & 0 & 42 \\
Fearful & 9 & 17 \\
Punishing-Cruel & 18 & 33 \\
Total Score & $4.4(2.7)$ & $7.0(3.7)$ \\
& &
\end{tabular}

Numbers are percent of group that endorsed the item $*<0.01 ; * *<0.001$

body ( 1 or 2 quadrants) while the widespread pain group was comprised of 12 women who reported pain in either 3 or 4 quadrants. The regional pain group marked an average of 2 areas on the body diagram; whereas the widespread pain group marked an average of 12 areas. The 
Table 4: Brief Pain Inventory by Pain Extent Subgroup

\begin{tabular}{lcc}
\hline Variable & Regional Pain & Widespread Pain \\
\hline Pain Worst & $3.1(1.9)$ & $6.6(2.3)^{* *}$ \\
Pain Least & $1.0(1.3)$ & $3.2(2.9)$ \\
Pain Average & $2.7(1.6)$ & $4.9(2.1)^{* *}$ \\
Pain Right Now & $1.4(1.4)$ & $5.2(2.4)^{* *}$ \\
Pain Interference & & \\
$\quad$ General Activity & $0.6(1.3)$ & $4.5(2.1)^{* *}$ \\
Mood & $1.0(1.8)$ & $4.8(2.2)^{* *}$ \\
Walking Ability & $0.6(1.5)$ & $4.2(2.0)^{* *}$ \\
Normal Work & $1.1(1.7)$ & $4.9(2.5)^{* *}$ \\
Relations with others & $0.4(0.9)$ & $4.2(2.6)^{* *}$ \\
$\quad$ Sleep & $2.3(3.2)$ & $5.4(2.9)$ \\
Enjoyment of Life & $1.3(1.0)$ & $5.2(2.3)^{* *}$ \\
\end{tabular}

Numbers are means and standard deviations.

$*<0.01 ; * *<0.001$

Table 5: Fibromyalgia Impact Questionnaire by Pain Extent Subgroup

\begin{tabular}{lcc}
\hline Variable & Regional Pain & Widespread Pain \\
\hline Physical Activity & $1.5(2.4)$ & $3.1(2.4)$ \\
Felt Good & $1.6(2.3)$ & $6.1(3.1)^{* *}$ \\
Missed Work & $0(0)$ & $1.9(3.0)$ \\
Job Difficulty & $1.2(2.1)$ & $5.2(2.4)^{* *}$ \\
Pain & $3.5(2.9)$ & $5.8(1.5)$ \\
Fatigue & $4.3(3.4)$ & $8.0(1.2)^{*}$ \\
Unrested & $3.4(2.6)$ & $7.2(1.7)^{* *}$ \\
Stiffness & $3.0(3.3)$ & $5.8(2.6)$ \\
Anxiety & $1.1(2.2)$ & $4.6(2.8)^{*}$ \\
Depression & $1.4(2.4)$ & $4.3(3.0)$ \\
FIQ Total Score & $20.9(13.2)$ & $52.0(15.1)^{* *}$ \\
\hline
\end{tabular}

Number are means and standard deviations

$*<0.01$; $* *<0.001$

demographic, surgery and treatment characteristics of the sample are shown in Table 1. All subjects were at least 1 year post-surgery, radiation and chemotherapy and $80 \%$ were within 5 years of initial treatment. Sixty-five percent were on anti-estrogen therapy with either tamoxifen or remedex at the time of the study.

Pain characteristics summarized in Table 2 indicated that a majority in both groups experienced the onset of their chronic pain immediately after surgery with a lesser number noting the onset weeks to months later. Those with regional pain were much more likely to describe their pain as intermittent while those with widespread pain were evenly split in this regard. Those with widespread
Table 6: FACT-B and SF-36 by Pain Extent Subgroup

\begin{tabular}{lcc}
\hline Variable & Regional Pain & Widespread Pain \\
\hline FACT-B & & \\
Physical Well-Being & $22.9(2.9)$ & $16.0(4.7)^{* *}$ \\
Social/Family Well-being & $19.4(4.8)$ & $15.7(6.1)$ \\
Relationship with Doctor & $6.1(1.9)$ & $4.8(2.5)$ \\
Emotional Well-being & $20.1(2.8)$ & $15.7(4.0)^{* *}$ \\
Functional Well-being & $22.1(3.9)$ & $16.7(5.7)^{*}$ \\
Additional Concerns & $24.3(6.7)$ & $16.5(5.5)^{*}$ \\
SF-36 & & \\
General Health & $60.3(19.5)$ & $57.9(21.4)$ \\
Physical Functioning & $68.6(23.9)$ & $48.7(17.1)^{*}$ \\
Role-Physical & $63.6(39.3)$ & $18.7(24.1)^{*}$ \\
Bodily Pain & $60.4(14.4)$ & $41.4(14.1)^{*}$ \\
Vitality & $41.4(16.3)$ & $27.1(14.2)$ \\
Social Functioning & $78.4(20.2)$ & $61.4(22.3)$ \\
Role-Emotional & $75.7(30.1)$ & $47.2(38.8)$ \\
Mental Health & $61.1(13.9)$ & $51.3(14.3)$ \\
\hline
\end{tabular}

$*<0.01 ; * *<0.001$

Numbers are means and standard deviations

pain were more likely to rate their pain as worse when depressed or fatigued, and observed a worsening of pain with exercise, rest, cold or contact with clothing. All subjects in the widespread pain group rated medication as at least somewhat effective for relieving their pain. Only $56 \%$ of those with regional pain noted any pain relief from medication. Of the 23 subjects, 5 were taking no medications, 12 were on non-steroidal antiinflammatories, 3 were taking narcotic pain relievers, 2 were on neurontin and 1 took glucosamine.

As seen in Table 3, a majority of both groups described their pain as aching, tender, and sharp. A higher percentage of the regional pain group described their pain as throbbing and stabbing while a higher percentage of the widespread pain group described it as shooting, cramping, gnawing, hot-burning, heavy, and splitting. They were also much more likely to use the words that described the emotional components of pain, such as tiring-exhausting and sickening. Overall, those with widespread pain endorsed more items than those with regional pain.

Intensity of pain as well as multiple measures of pain interference on the BPI were all higher in the widespread pain group with the differences reaching statistical significance on all but three items (Table 4). Results of the FIQ (Table 5) were similar. The widespread pain group had higher impact scores and the differences between the two groups reached statistical significance on 5 of the 10 items as well as the total FIQ score. The FACT-B and SF-36 results shown in Table 6 revealed a statistically significant difference in the two groups on subscales measuring phys- 
Table 7: Quality of Life Scale (QOLS) by Pain Extent Subgroup

\begin{tabular}{lcc}
\hline Variable & $\begin{array}{c}\text { Regional } \\
\text { Pain }\end{array}$ & $\begin{array}{c}\text { Widespread } \\
\text { Pain }\end{array}$ \\
\hline Material Comforts & $5.0(1.7)$ & $5.0(1.6)$ \\
Health & $4.2(1.5)$ & $3.2(1.3)$ \\
Relationships with relative & $4.8(1.5)$ & $4.7(1.2)$ \\
Having and rearing children & $5.0(1.3)$ & $5.4(1.2)$ \\
Relationship with spouse or partner & $5.5(1.1)$ & $5.0(1.9)$ \\
Having Close friends & $6.0(0.9)$ & $5.7(1.4)$ \\
Helping Others & $5.9(0.8)$ & $5.3(1.3)$ \\
Civic Activities & $5.1(1.6)$ & $4.8(1.3)$ \\
Intellectual Development & $5.7(1.3)$ & $4.8(1.1)$ \\
Understanding Self & $5.4(0.8)$ & $5.0(1.3)$ \\
Occupational Role & $4.9(1.7)$ & $4.2(1.4)$ \\
Creative expression & $5.4(1.2)$ & $4.2(1.6)$ \\
Socializing & $5.4(1.3)$ & $4.4(1.6)$ \\
Passive recreation & $6.2(0.9)$ & $5.7(1.4)$ \\
Active Recreation & $4.7(1.9)$ & $3.4(1.1)$ \\
Independence & $5.9(1.8)$ & $5.1(1.1)$ \\
QOLS Total Score & $85.2(10.0)$ & $76.0(15.3)$ \\
\hline
\end{tabular}

Numbers are means and standard deviations

ical health status and well-being. Table 7 lists the items on the QOLS along with the total score. Although most of the scores were lower in the widespread pain group, none reached statistical significance.

\section{Discussion}

The results of this pilot study describe two groups of post breast cancer surgery patients who were similar in demographic, surgery and pain characteristics but markedly different in the impact that pain has on their health status and functioning. Widespread pain, which not been studied as a separate entity in this population, interferes with most aspects of these women's lives to a much greater degree than does regional pain.

For many patients, the chronic pain began immediately after surgery or early in the post-surgical treatment period. This type of onset is well recognized by breast cancer surgeons $[23,50]$ and a number of efforts are being made to treat this lingering effect [20]. However, chronic pain that begins later in the post-surgical period after weeks or months may be less likely to be recognized and aggressively treated. Notably, FMS tends to be diagnosed only after a long period of persistent pain and failed local treatment.

Although a majority of patients described their pain as worse when they were fatigued, a description often voiced by people with chronic pain, the higher percentage of those with widespread pain who experienced worse pain with after exercise, rest or exposure to cold is similar to those with the specific syndrome of FMS. Increased sensitivity to muscle activity or inactivity as well as sensory input, such as cold, noise, bright lights or smells, are common to people with FMS $[29,30]$. It appears that women in the widespread pain group resemble those with FMS in some significant ways.

It was interesting and unexpected that those with widespread pain described getting at least some relief from pain medications as many patients with chronic pain get little relief from medication. On the other hand, it is also discouraging to note that many patients with regional pain did not get relief from medication as major strides have been made to aggressively treat neuropathic pain with tricyclic antidepressants and anticonvulsants such as gabapentin [20].

There were few differences in pain descriptions between the two groups with the exception of the emotional impact of pain, which was experienced more, by the widespread pain group. One item, hot-burning, was unexpectedly endorsed more by the widespread pain group, when one might have expected that sensation to be more descriptive of neuropathic pain experienced by the regional pain group.

Both the BPI and the FIQ clearly differentiated the regional from the widespread pain group. As expected, the widespread group was much more impacted. On the FIQ, their overall scores were very close to those noted in FMS studies [42,51]. The regional pain group's scores were much lower and closer to those of rheumatoid arthritis patients who have been used as a comparison group in studies of the psychometric properties of the FIQ [52]. The degree of pain interference with activities and enjoyment of life measured by the BPI was three to four times greater in the widespread pain group when compared to the regional pain group.

Three of the questionnaires, SF-36, FIQ and FACT-B, contain a subscale that focuses on physical functioning or well-being and they are moderately correlated with each other $(\mathrm{r}=.58-.60)$. Yet, the FIQ physical activity subscale scores were not significantly different between the two groups while the other two subscales were. The FACT-B physical well-being subscale focuses on symptoms such as fatigue, pain and feeling ill, which would be expected to bother the widespread pain group more. Both the SF-36 and FIQ subscales focus on normal physical activities such as walking, climbing stairs, household activities. However, the SF-36 includes vigorous activities such as walking more than a mile and climbing several flights of stairs, activities that might be much more difficult for a person with widespread pain to accomplish while the FIQ sub- 
scale focuses mostly on every day household activities. Thus, it would seem important to clearly identify the contents of subscales such as the ones used in this pilot study before attempting to compare groups of patients on health status and functioning measures.

Although the widespread pain group' total QOLS score was lower than the score of the regional pain group, neither it nor the individual item scores reached statistical significance. The regional pain group's mean total score was as high as those seen in healthy groups while the widespread pain group's score was lower but not as low as the scores seen in untreated FMS patients [34]. The QOLS is an individual satisfaction instrument that focuses on a wide range of domains that are not directly health-related. Scores on the QOLS have been shown to vary more in response to mood and other psychological states than to physical functioning [49]. The widespread pain group had significantly more psychological distress on the measures contained within the FIQ, SF-36 and FACT-B. This may account for the lower QOLS scores that in a larger sample would have reached statistical significance.

There are a number of limitations to this study. First, the sample was one of convenience and cannot be construed as representative of the post-breast cancer surgery population. Second, the sample was small and the number of variables large. Thus, the findings must be viewed with caution as some of the significant differences could have occurred by chance. Third, it is possible that adjuvant therapy rather than the surgery could have caused the chronic pain since both radiation and chemotherapy are known to produce symptoms of fatigue, pain and poor sleep in many patients. However, all patients were at least 1 year post adjuvant therapy and there were no differences in pain severity or other symptoms based on whether or not the subject had gotten adjuvant therapy. In addition, those on current tamoxifen therapy did not differ from those who were not.

This pilot study was carried out primarily to characterize two groups of post-breast cancer surgery patients with different pain patterns. A secondary purpose was to test a set of instruments to see if they would differentiate the two groups. Several of the instruments yielded scores that were significantly different on pain, health status, and interference with multiple aspects of life. This finding points to the need to study chronic pain further after breast cancer surgery and especially attend to the group of women whose pain has become widespread.

\section{Conclusion}

This preliminary work suggests that the women in this study who experienced widespread pain after breast cancer surgery had significantly more pain impact and lower health status than those with regional pain. Further comparative work should be undertaken.

\section{Authors' contributions}

CSB took major responsibility for conceptualization of the project, wrote the proposal, obtained funding, analyzed the data and wrote the complete draft of the paper

KDJ assisted in the literature review and writing of the proposal, oversaw the data collection and data entry, assisted in the analysis of the data, and reviewed drafts of the manuscript. Both authors reviewed the final draft of the manuscript and approved its contents.

\section{Acknowledgements}

The authors gratefully acknowledge the work of Vicky Crosby who collected the data.

\section{References}

I. Garfinkel L, Boring CC, Health CWJ: Changing trends: an overview of breast cancer incidence and mortality. Cancer 1994, 74:222-227.

2. Ries LAG, Wingo PA, Miller DS, Howe HL, Weir HK, Rosenberg HM, Vernon SW, Cronin K, Edwards BK: The annual report to the nation on the states of cancer, 1973-1997. Cancer 2000, 88:2398-2424.

3. Peto R, Boreham J, Clarke M, Davies C, Beral V: UK and USA breast cancer deaths down $25 \%$ in year 2000 at ages 20-69. Lancet 2000, 355:1822.

4. Smart CR, Byrne C, Smith RA, Garfinkel L, Letton AH, Dodd GD, Beahrs $\mathrm{OH}$ : Twenty-year follow-up of the breast cancers diagnosed during the Breast Cancer Detection Demonstration Project. CA Cancer J Clin 1997, 47: I34- 149.

5. Bonneterre J, Schraub S, Lecomte S, Mercier M: Quality of life as an outcome in breast cancer: clinical application. Pharmacoecon 1996, 9(suppl 2):23-29.

6. Hurny C, Bernhard J, Coates A: Quality of life assessment in the International Breast Cancer Study Group: past, present and future. Recent Result Cancer Res 1998, I 52:390-395.

7. Bardwell WA, Major JM, Rock CL, Newman VA, Thomson CA, Chilton JA, Dimsdale JE, Pierce JP: Health-related quality of life in women previously treated for early-stage breast cancer. Psych-oncol 2003, 13:595-604.

8. Schag CA, Ganz PA, Polinsky ML, Fred C, Hirji K, Petersen L: Characteristics of women at risk for psychosocial distress in the year after breast cancer. J Clin Oncol 1993, I I:783-793.

9. Glover J, Dibble SL, Dodd MJ, Miaskowski C: Mood states of oncology outpatients: does pain make a difference? J Pain Symptom Manage 1995, 10:120-128.

I0. Strang P: Existential consequences of unrelieved cancer pain. Palliative Med 1997, I I:299-305.

II. Amichetti M, Caffo O: Pain after quadranectomy and radiotherapy for early-stage breast cancer: Incidence, characteristics and influence on quality of life. Oncology 2003, 65:23-28.

12. Caffo O, Amichetti M, Ferro A, Lucenti A, Valduga F, Galligioni E: Pain and quality of life after surgery for breast cancer. Breast Cancer Res Treat 2003, 80:39-48.

13. Fortner BV, Stepanski EJ, Wang SC, Kasprowicz S, Durrence HH: Sleep and quality of life in breast cancer patients. J Pain Symptom Manage 2002, 24:47। -480.

14. Poole K, Fallowfield LJ: The psychological impact of post-operative arm morbidity following axillary surgery for breast cancer: a critical review. Breast 2002, I I:8I I-87.

15. Rietman JS, Dijkstra PU, Debreczeni R, Geertzen JHB, Robinson DPH, de Vries J: Impairments, disabilities and health related quality of life after treatment for breast cancer: a follow-up study $\mathbf{2 . 7}$ years after surgery. Disability Rehabil 2004, 26:78-84.

16. Randal J: Post-mastectomy pain found to common: treatment options sparse, but growing. J Natl Cancer Inst 1998, 90:73|-732. 
17. Stevens PE, Dibble SL, Miaskowski C: Prevalence, characteristics and impact of postmastectomy pain syndrome: an investigation of women's experiences. Pain 1995, 6 I:6I-68.

18. Wallace MS, Wallace AM, Lee J, Dobke MK: Pain after breast surgery: a survey of 282 women. Pain 1996, 66:195-205.

19. Blunt C, Schmiedel A: Some cases of severe post-mastectomy pain syndrome may be caused by an axillary haematoma. Pain 2004, 108:294-296.

20. Jung BF, Ahrendt GM, Oaklander AL, Dworkin RH: Neuropathic pain following breast cancer surgery; proposed classification and research update. Pain 2003, 104: I- I3.

2I. Tasmuth T, Karaja M, Blomqvist C, von Smitten K, Kalso E: Treatment-related factors predisposing to chronic pain in patients with breast cancer. Acta Oncologica 1997, 36:625-630.

22. Warmuth MA, Bowen G, Prosnitz LR, Chu L, Broadwater G, Peterson B, Leight G, Winer EP: Complications of axillary node dissection for carcinoma of the breast: a report based on a patient survey. Cancer 1998, 83:।362-1368.

23. Legeby M, Segerdahl M, Sandelin K, Wickman M, Ostman K, Olofsson $C$ : Immediate reconstruction in breast cancer surgery requires intensive post-operative pain treatment but the effects of axillary dissection may be more predictive of chronic pain. Breast 2002, I I: I56-I62.

24. Carpenter JS, Andrykowski MA, Sloan P, Cunningham L, Cordova MJ, Studts JL, McGrath PC, Sloan D, Kenady DE: Postmastectomyl postlumpectomy pain in breast cancer survivors. J Clin Epidemiol 1998, 5 I: I285-1292.

25. Andrykowski MA, Curran SL, Carpenter JS, Studts JL, Cunningham L, McGrath PC, Sloan DA, Kenady DE: Rheumatoid symptoms following breast cancer treatment: a controlled comparison. J Pain Symptom Manage 1999, I 8:85-94.

26. Nyren O, Yin L, Josefsson S, McLaughlin JK, Blot WJ, Engqvist M, Hakelius L, Boice JD Jr, Adami H-O: Risk of connective tissue disease and related disorders among women with breast implants: a nation-wide retrospective cohort study in Sweden. BMJ 1998, 3 16:417-422.

27. Croft P, Rigby AS, Boswell R, Schollum J, Silman A: The prevalence of chronic widespread pain in the general population. J Rheumatol 1993, 20:710-713.

28. Wolfe F, Ross K, Anderson J, Russell IJ, Hebert L: The prevalence and characteristics of fibromyalgia in the general population. Arthritis Rheum 1995, 38:19-28.

29. Staud R, Cannon RC: Temporal summation of pain from mechanical stimulation of muscle tissue in normal controls and subjects with fibromyalgia. Pain 2003, I 02:87-95.

30. Geisser ME, Casey KL, Brucksch CB: Perception of noxious and innocuous heat stimulation among healthy women and women with fibromyalgia. Pain 2003, I 02:243-250.

31. Buskila D, Neumann L, Vaisberg G, Alkalay D, Wolfe F: Increased rates of fibromyalgia following cervical spine injury. A controlled study of 161 cases of traumatic injury. Arthritis Rheum 1997, 40:446-452.

32. Sartariano WA, Ragland DR, DeLorenze GN: Limitations in upper-body strength associated with breast cancer: a comparison of black and white women. J Clin Epidemiol 1996, 49:535-544.

33. Waylonis GW, Perkins RH: Post-traumatic fibromyalgia: a longterm follow-up. Am J Phys Med Rehabil 1994, 73:403-4I2.

34. Burckhardt CS, Clark SR, Bennett RM: Fibromyalgia and quality of life: a comparative analysis. J Rheumatol I993, 20:475-479.

35. Wolfe F, Anderson J, Harkness D: Work and disability status of persons with fibromyalgia. J Rheumatol 1997, 24: I I7I-I I78.

36. Wolfe F, Smythe HA, Yunus MB, Bennett RM, Bombardier C, Goldenberg DL, Tugwell P, Campbell SM, Abeles M, Clark P, Fam AG, Fiechtner J], Franklin CM, Gatter RA, Hamaty K, Lessard J, Lichtbroun AS, Masi AT, McCain GA, Reynolds WJ, Romano TJ, Russell J, Sheon RP: The American College of Rheumatology 1990 criteria for the classification of fibromyalgia: Report of the Multicenter Criteria Committee. Arthritis Rheum 1990, 33:160-I72.

37. Daut RL, Cleeland CS, Flanery RC: Development of the Wisconsin Brief Pain Questionnaire to assess pain in cancer and other diseases. Pain 1983, I7:197-210.

38. Cleeland CS, Nakamura Y, Mendoze TR, Eduwards KR, Douglas J Serline RC: Dimensions of the impact of cancer pain in a four country sample: new information from multidimensional scaling. Pain 1996, 67:267-273.
39. Melzack R: The short-form McGill Pain Questionnaire. Pain 1987, 30:191-197.

40. Dudgeon D, Raubertas RF, Rosenthal SN: The short-form McGill Pain Questionnaire in chronic cancer pain. J Pain Symptom Manage 1993, 8:191-195.

41. Burckhardt CS, Bjelle A: A Swedish version of the short-form McGill Pain Questionnaire. Scand J Rheumatol I994, 23:77-8I.

42. Burckhardt CS, Clark SR, Bennett RM: The Fibromyalgia Impact Questionnaire: Development and validation. J Rheumatol 1991, I 8:728-734.

43. Cella DF, Tulsky DS, Gray G: The Functional Assessment of Cancer Therapy scale: development and validation of the general measure. J Clin Oncol 1993, I I:570-579.

44. Brady MJ, Cella DF Mo F, Bonomi AE, Tulsky DS, Lloyd SR: Reliability and validity of the Functional Assessment of Cancer Therapy-Breast quality of life instrument. J Clin Oncol 1997, I 5:974-986.

45. Ware JE, Sherbourne CD: The MOS 26-item Short-Form Health Survey (SF-36). I. Conceptual famework and item selection. Med Care 1992, 30:473-48I.

46. Broeckel JA, Jacobsen PB, L B, Horton J, Lyman GH: Quality of life after adjuvant chemotherapy for breast cancer. Breast Cancer Res Treat 2000, 62:141-150.

47. Neumann L, Berzak A, Buskila D: Measuring health status in Israeli patients with fibromyalgia syndrome and widespread pain and healthy individuals: utility of the short form 36-item health survey (SF-36). Semin Arthritis Rheum 2000, 29:400-408.

48. Burckhardt CS, Woods SL, Schultz AA, Ziebarth DM: Quality of life of adults with chronic illness: a psychometric study. Res Nurs Health 1989, I 2:347-354.

49. Burckhardt CS, Anderson KA, Archenholtz B, Hagg O: The Flanagan Quality of Life Scale: Further evidence of validity. Health Quality Life Outcome I:59. (23 October 2003).

50. Schierle C, Winograd JM: Radiation-induced brachial plexopathy: review. Complication without a cure. J Resconstr Microsurg 2004, 20:149-I52.

5I. Bennett RM, Burckhardt CS, Clark SR, O'Reilly CA, Wiens AN, Campbell SM: Group treatment of fibromyalgia: description and results of a six-month out-patient program. J Rheumatol 1996, 23:521-528.

52. Hedin P-J, Hamne M, Burckhardt CS, Engstrom-Laurent A: The Fibromyalgia Impact Questionnaire, a Swedish translation of a new tool for evaluationn of the fibromyalgia patient. Scand J Rheumatol 1995, 24:69-75.

Publish with Bio Med Central and every scientist can read your work free of charge

"BioMed Central will be the most significant development for disseminating the results of biomedical research in our lifetime. "

Sir Paul Nurse, Cancer Research UK

Your research papers will be:

- available free of charge to the entire biomedical community

- peer reviewed and published immediately upon acceptance

- cited in PubMed and archived on PubMed Central

- yours - you keep the copyright

BioMedcentral 